\title{
INTERCULTURAL EDUCATION RECONSIDERED: A DISCUSSION BASED ON COMMUNICATION THEORY AND WITH SPECIAL REFERENCE TO RELIGIOUS EDUCATION. ${ }^{1}$
}

\author{
Geir Skeie \\ University of Stavanger \\ Norway
}

\begin{abstract}
The article discusses how the concept intercultural can be used to understand human relations in general and educational settings in particular. Drawing on the theory of intercultural communication, it is argued that all human encounters may be interpreted as being intercultural. Intercultural situations in a more narrow sense occur when one actor experiences, expects or introduces culture as part of the interaction. Educationally, such situations may be both constructive and counterproductive. In order to deal with intercultural settings, the teacher should first analyse the situation in light of knowledge about cultures and religions as well as the sociocultural context. Then, one strategy is to focus on culture by enhancing complexity breaking down stereotypes, another is to avoid culture, by reducing complexity and focusing on the school subject. By alternating between these two strategies the teacher contributes towards establishing a third culture in the classroom, facilitating both reflection and negotiation.
\end{abstract}

Key Concepts: Intercultural, communications, interaction, socio-cultural context, stereotyping

\begin{abstract}
Introduction
The emergence of intercultural education in Norway has as its background the immigration from late 1960's onwards which has changed the Norwegian society significantly by introducing a more visible traditional plurality of ethnic and religious groups. Plurality in itself was not unknown, but the focus had mainly been on the individual, and on what I have elsewhere called modern plurality (Skeie, 2002). The new plurality was mainly conceived as a plurality of groups - it included immigrants from South, and many of them belonging to non-Christian religions. This immigration introduced a difference to Norwegian society that had further reaching consequences than the volume of immigration would suggest. Among the consequences was also the recognition of existing cultural differences with long historical presence in Norway. This has improved the situation particularly for the marginalised, indigenous Sami population. Another result has been to increase self-reflection on the meaning of being Norwegian, including rewriting parts of the history of Norway. A newly published three-volume history of immigration to the country has shown that intercultural relations are permanent parts of society, not the recent phenomenon many thought it to be (Kjelstadli, 2003).
\end{abstract}

This article has benefitted from discussions with colleagues at SIK - Centre for Intercultural Communication in Stavanger, Norway. 
As a result of the changes towards a more visible and openly multicultural Norway, also the welfare state system has attempted to adjust itself. The Parliament and different governments have issued laws, rules and regulations as well as political statements in order to deal with the challenges of a multicultural society. In addition different professions within the sectors of the welfare system have taken initiatives to secure that people belonging to all cultural groups benefitted from their rights according to law. Many individual teachers, social workers, health workers and others have shown solidarity with cultural minorities. Call for improvements in the welfare system has come from below and from above, however strong political controversies have also appeared.

Gradually the institutions of higher education, in particular those educating the groups of professionals mentioned above, have started to integrate multicultural perspectives into their curricula, and research has been done in order to establish a more solid base of knowledge about the field. In many cases the researchers who first took interest in these issues did it more out of principle and personal commitment than based on institutional priorities or good funding possibilities. Multicultural perspectives are now often declared to be central both in education and in research, even if this is not always put into practice. One example of the official priorities in this field is the establishment of a National Centre for Multicultural Education from January $2004 .^{2}$ Intercultural education can therefore be seen as part of a broad political strategy to secure a successful integration of different groups into one multicultural society.

Among professionals, the ideal of a multicultural society is not only a question of opinions or political strategies, even if this certainly plays a part. It is also considered the duty of a professional teacher, social- or health worker to achieve certain aims connected to education, social participation or health. Their work situation is therefore directly influenced by ideals about a well functioning multicultural society. Some have their jobs directly linked to the work with immigrants or refugees, while others are more indirectly involved. In their daily work these professionals combine scientific knowledge with practical as well as normative knowledge. They often speak positively of multicultural understanding or multicultural community and a purely descriptive approach to the issue therefore seems insufficient. In a wider context of research, as well as public debate, concepts in this field are generally shown to be contested.

In order to reflect more systematically on issues of intercultural education, it seems appropriate to clarify what constitutes an intercultural situation in the first place. How is this type of situation understood and managed? What is specific for intercultural meetings between people, and therefore different from encounters? The following reflections make use of theory about intercultural communication and proceed to raise some questions concerning intercultural education. Finally, the question is asked what this means for religious education. Is it possible that religious education can serve as a special case of intercultural education, and therefore giving deeper insight into this complex field? Even if the following reflections are situated in a Norwegian context, they are intended to be of more general significance drawing also on international research.

2 The Centre is situated at The University College of Oslo, and is mainly a body for carrying out the strategies of the Ministry of Education, particularly by stimulating local and regional activities including networking between schools, colleges and education authorities. Web site: http://www.hio.no/content/view/full/4855 


\section{People meeting People}

The notion intercultural seems to assume that something is happening between cultures. This implies that cultures must be identifiable as separate entities. The relationship between such entities must in some way include the possibility of communication, and when it comes to intercultural education this communicative aspect of course is vital. In discussions about multicultural schools, many mention the challenge of communicating between cultures. All this gives good reason to believe that reflections on intercultural communication should be of interest to those who are preoccupied with intercultural education.

The research tradition related to intercultural communication goes back to the participation of United States in World War Two. The soldiers had to deal with situations in socio-cultural contexts very different from their background at home and to solve problems that could not be adequately solved by force (Dahl, 1995). Research was conducted, and handbooks developed based on ethnographic and other knowledge. After the war similar challenges faced the growing international business life, with multinational corporations in need of knowledge about different cultures in a global market.

The intercultural communication research is still producing handbooks about how westerners can improve communication with foreign partners in business or other relations (Landis and Bhagat, 1996; Godykunst and Moody, 2002). The research has also produced complex theories about intercultural communication. These theories are often based on a process paradigm with transmission as a root metaphor (Haus, 2003a; 2003b). The core meaning of this metaphor in communication theory is to see communication as a process of carrying a message from a sender to a receiver. In the case of intercultural communication, people are seen to represent cultures, with meaning embedded in their background culture. Therefore messages in communication are carrying with them elements of this culture. The possibility of understanding is therefore seen to be dependent on the ability of communicators to unpack meaning that is culturally conditioned (Dahl, 2001). This may be expressed by referring to the message being influenced by cultural codes or passed through cultural filters. According to theory there is more chance of the intended meaning getting through without distortion from the one to the other partner in communication if the codes or filters are made visible, hence the importance of knowledge about cultures. A theoretical challenge seems to be how to include the increasing amount of factors or dimensions of communication that are shown to influence understanding between people coming from different cultural backgrounds.

Today it is common within the field of intercultural communication to criticise transmission models of communication for being simplistic. But to understand communication, as a process, does not mean that it has to be viewed as a simple one-way procedure, based on an instrumental approach. Even within a transmission perspective it can be understood as exchange of and interpretation of signs and messages between people (Dahl, 2001:64). This understanding of the intercultural communication process is using impulses from semiotics and can also be further modified by underlining the activity of the actors in communication. Instead of seeing the communicating partners as people simply representing different cultural communities, one may ask if they consider themselves so different that this systematically influences their attribution of meaning (Dahl, 2001:64).

This actor-oriented perspective prefers to speak of inter-cultural communication in those cases where (some of) the participants in communication have chosen to make culture relev communication is opened up towards the social situation or context where communication is taking place. Instead of seeing successful communication as a question of transmission of meaning it is understood as a contextually situated negotiation of meaning 
between actors. Opposing meanings are seen as different, but in principle equally valid interpretations of reality. The question of whether an objective reality exists is left open, and the social construction of knowledge is emphasised.

Using this perspective it is considered relevant to speak of intercultural communication particularly if the partners in communication themselves activate culture. By doing this the actor- and context oriented negotiation-perspective transcends the metaphor of transmission so basic to many theories of communication. Some theorists of intercultural communication therefore consider the processes of inter-cultural and intra-cultural communication to be of basically the same nature (Jensen, 1998).

If it is the actors who themselves bring culture into the communication, instead of culture being an inseparable (implicit) part of the message itself, new questions arise: How do the actors activate culture? And why do they do this? In the end these are empirical questions, but generally speaking they have as much to do with interaction as with culture. Analytically we can see this as a sequence in two steps:

- The first step has to do with the characteristics of the kind of situations when culture is likely to be made relevant by an actor? Possibly it is in the interest of one or more actor to bring culture into the situation in order to pursue a particular intention. If this is done more indirectly, or even unconsciously, by including in the communication cultural elements that are not shared, it is more likely to cause genuine misunderstanding.

- The second step has to do with what happens in communication after culture has been introduced. This starts a new dynamic, not always fully controlled by the actor who introduced culture, because the other actor present has his or her own goals to pursue. At this point the negotiation phase begins.

In order to manage intercultural communication successfully one needs the ability to employ an observing meta-perspective on the social situations one engages in. This includes making use of hypotheses about cultural variation and the meaning of signs. In other words, we are speaking about the competence to manage multiple meaning in social situations and to negotiate meaning without loosing track of the original reason for starting the communication sequence. From a research perspective this is quite complicated to unravel, but it is constantly happening when people meet people, due to the dynamics of culture.

On the one hand culture can be understood almost like a thing, something we have, that can be brought into conversation or interaction like an artefact, or activated as a play with certain rules. This is the dimension of culture that is most easy to see in the first step mentioned above. On the other hand culture can be understood as a process, as something we $d o$, where meanings are created, communicated, contested and changed at the same time. This is what is most visible in the second step. The dynamic of a situation is changed by introduction of the culture thing and from that another (cultural) process starts. This does not mean that the two dimensions are not always present, only that they are not as visible. At least in this sense we can speak of cultures meeting each other.

\section{Cultures meeting Cultures}

The two opposing dimensions mentioned are constantly in motion or reflecting each other. Culture is like a flow of meaning transmitted and transformed at the same time, and this is highly relevant for understanding intercultural communication. The essentialist concept of culture that often seems so functional in the beginning of an encounter, gradually fades away or enters into the background, and stereotypes give way to a more complex under- 
standing. This second understanding sees culture as something constructed between people, but not only as a play of signs, it is socially situated. The two dimensional, or double concept of culture therefore includes the narrow, essentialist one, without annihilating it. Fredrik Barth has managed to bridge the gap between the essentialist and the processoriented perspective in what he calls a critical concept of culture in complex societies:

- Meaning is a relation between a configuration of signs and an observer, not something baked into and preserved within a specific cultural expression.

- Culture is distributed in a population, every element is shared with somebody, but not with others.

- Actors are (always and unavoidably) positioned.

- Events are formed by different kinds of interplay between material causality and social interaction, and are therefore differing from the intentions of the individual actors (Barth, 1994: 120). ${ }^{3}$

Barth's conceptualisation seems to avoid some possible weaknesses of extreme constructionist approaches. Culture is not only seen as relations between signs, but simultaneously as social interaction. The collective aspects of culture, being shared within a group, and not only negotiated are also included. Within this concept of culture it seems possible to locate intercultural encounters as something specific. It may refer to a situation where actors focus on how culture is distributed: What is shared by whom, and not by others? The question that remains is when and why this particular focus appears?

From a common-sense point of view, culture often becomes visible at the point when communication is not working as expected. While taking part in social situations, people sometimes experience incompetence or surprise, manifested as misunderstandings, unexpected reactions or different opinions about what has been agreed upon. When such experiences make it difficult for co-actors to understand each other, it reduces their feeling of control in the situation and therefore the flexibility of the individual. Persons do not appear as fully independent actors, instead their actions seem to be governed by something else, namely their culture.

Such experiences may set off reflection about the distribution of culture, and the situation might be interpreted as a case of intercultural encounter. In such encounters the relations between culture and person seem to be different from ordinary communication in the sense that culture understood as certain group-based patterns of behaviour seem to dominate over the individuality of persons following them. If such patterns of behaviour are identified, but not shared or even understood, they seem from a common-sense point of view to be strange, unfamiliar or different. Increasingly today the word cultural is used, in particular if ethnic, religious or other collective differences seem to be present. From this point a reification process may begin and the identified culture becomes basis for interpretation.

In cases when patterns of behaviour or verbal communication are not understood, culture may serve as a working hypothesis about hidden patterns. In this way the Other in communication is not seen as irrational, but rather as culturally conditioned. On the basis of such experiences expectations are formed, waiting for future situations that might be similar. These experiences may be called moments of unequal sharing, or intercultural situations.

Even without such specific experiences as a background, the idea of cultures meeting each other may come up as an expectation. In this case the focus is primarily on a

Translated from Norwegian by Geir Skeie. 
(imagined) frame of reference or commitment to a cultural community, rather than on the subject one is interacting with. The reason is therefore not necessarily objective differences in culture between the inter-actors themselves. The expectation is based on the actors believing themselves and/or the Other to be committed to a certain package of basic values and norms for action.

When one actor considers the Other to be mainly representing a culture, also the actor thereby commits him/herself to a different culture. Such is the case if one actor declares him or herself to represent a specific culture, implying that the other does not. This apparent symmetrical commitment to different cultures is however not so clear-cut and not always recognised. One important reason for this is the unequal distribution of power. The most powerful part in the interaction often tends to universalise his/her own values, and by this to force the other into a cultural (different) position. This is often the case in relations between a powerful majority and a less powerful minority.

The reality of unequal power is one reason to reject the extreme constructivist idea that communication across cultural differences is only a play of signs and a question of interpretation. Like power, values, beliefs, practices and knowledge are also not fully shared, but distributed in a population. Therefore, successful communication in complex societies depends on the ability to establish situated and limited codes for communication and action in order to solve common problems. The development towards a more multicultural society in Norway seems to introduce some quite unfamiliar traditions to the majority population, but it can also be seen to add only more variations to an already plural culture. Immigration to many western countries like Norway has increased the focus on culture, and this is interacting with the fact that late modernity itself is full of culturalised encounters. Differences like young/old, male/female, countryside/town, rich/poor have a long story already, and the more recent and subtle differences in young people's life styles are also well known. These differences can be seen as reified or essentialised cultures, used to reduce complexity in interaction even if they do not have the aura of religion or ethnicity. Such cultures are not natural phenomena, but have to be made relevant in social situations by humans for some reason.

The mixture of differences based on modern and traditional plurality makes a straightforward concept of intercultural communication problematic. The concept is, however, relevant if it is understood in terms of a two-dimensional concept of culture. This concept of culture is paralleled by a narrow and a broad concept of intercultural communication. The narrow concept of intercultural communication covers situations where an actor has made culture central or it is seen as such by an observer (the first step). It focuses on the possibilities of misunderstandings and on how signs and meaning may be clarified in relatively controlled situations. This narrow understanding corresponds to the concept of culture as a thing, as something distributed. In this case knowledge based on an essentialist perspective of culture may have some value.

On the other hand we have a broad concept of intercultural communication. This is more analytic, more experience-distant, and is more directed towards the study of interaction in general. It focuses on how to understand situations better by seeing interaction as a complex negotiation between individuals representing, but also distancing themselves from groups and traditions, both consciously and unconsciously (the second step). This broad concept corresponds with a concept of culture as a flow of meaning and the totality captured by F Barths concept of culture in complex societies.

The narrow concept of intercultural communication fits situations when group-based identification related to ethnicity and/or religion is explicitly put forward or implicitly 
playing a role. In these situations knowledge about ethnic groups, religions and traditions is of great help, especially when this includes an appreciation of their complexity. In addition to this it is possible to learn from the skills that are used to manage modern plurality. In particular the ability to develop limited and situated, but functional codes for interaction seems useful. There is a challenge for professionals like teachers, social and health workers to prevent culture being used to manipulate or to establish asymmetric power relations in certain situations.

There are also some situations where it seems necessary to avoid a certain type of intercultural communication, because culture is mobilised as part of a power play. In this case it is useful to reduce the complexity in practical interaction, by avoiding that people are playing the culture card. But to have this as the only strategy would be to ignore the obvious reality of cultural differences completely. It should therefore be combined with another strategy going in the opposite direction, drawing on the broad concept of culture. This complimentary strategy can be described using the words of Gerd Baumann:

Try to unreify all accepted reifications by finding crosscutting cleavages. (...) Combine every method of questioning to every possible category around you, for the permutations are

endless when it comes to questioning reifications. (Baumann, 1999:141)

If teachers and other professionals were able to alternate between these two strategies it would possibly improve the quality of their work.

\section{Intercultural Education Reconsidered}

In the light of what has been said above, intercultural education can be seen to deal with the kinds of situations that have been described as intercultural situations, but within the specific setting of the school. This means that the cultural dimensions in communication are not only related to the intentions of actors, but also to the specific conditions and institutional framework of the educational system. Here teachers have a special role with focus on the organisation and facilitation of learning. They are placed at the interface between the young citizens and the social systems, and serving both as facilitators and as gatekeepers. This particularly difficult position can often put them in a situation where tension may arise between themselves and those they are serving.

The challenges are cultural in several meanings of the word; firstly teachers base their work on certain cultural values by formally representing society, secondly teachers interact with others within the school with their own, sometimes differing (cultural) values and norms. Thirdly, teachers are persons belonging to cultural groups and with specific beliefs, values and preferences. The borders between culture as something shared and something not shared, becomes an issue in their daily work on all these levels.

Teachers may find that the cultural composition of their class makes their job difficult to do. These difficulties range from misunderstandings to deep racial conflicts. In addition, children and youth sometimes experience or expect culture to be a difficulty in their interaction, and teachers have to deal with that. The intercultural competence that is needed both by teachers and children is not mainly constituted by descriptive knowledge about cultures, even if this can be a useful part, but by its normative basis: The ambition to facilitate communication and interaction in certain situations where culture is made relevant. For teachers this role as facilitator is part of their professional ethos.

Based on the reflections above, it is possible to suggest two different teacher strategies in dealing with intercultural situations in school, called complexity reduction and com- 
plexity enhancement. The complexity reduction is achieved by taking out the cultural element and by this reducing it to issues of interaction dealing with power, influence or control. The complexity enhancement strategy is going in the opposite direction, taking the intercultural definition of the situation at face value, but moving towards the intracultural by complicating the reified culture present in conversation and thereby deconstructing stereotypes. Teachers should have the skills to alternate between the two strategies, depending on the situation.

By alternating between reduction and enhancement of cultural complexity in the same multicultural group of learners, the teacher can contribute to creating a provisional third culture that works as a meeting place for cultural reflection and negotiation. How permanent or provisional this third culture needs to be, depends on the aims of the situation and the scale of communicative or interaction problems involved. It can vary from a short time-out in a class lesson, to a systematic long-term programme in a conflict-ridden school. In order to manage and take the lead in intercultural situations, the practitioner has to be clear on his/her selfunderstanding as a teacher as well as being able to reflect critically upon practice.

What is less needed, but sometimes overstated by insecure practitioners and wellmeaning outsiders, is abstract knowledge about cultures in general as well as specific knowledge about cultural groups in particular. It is not clear how content knowledge about cultures automatically will inform teachers' actions in a multicultural society. On the other hand, this kind of knowledge may be of great importance particularly if it is clearly related to the work in a local school and to the teaching of subject matter. An example of this is how ethnographic skills and insight may be of great value to the teacher in religious education (Nesbitt, 2004). Good teachers have the potential to act adequately in intercultural situations based on a context-sensitive and reflexive self-understanding as professionals that includes an open and democratic vision of the educational enterprise.

\section{The Case of Religious Education}

In Norway, as in several other countries, one important aim for the religious education subject is to be instrumental in creating harmony between cultural groups. This is being done partly by supporting knowledge about different religions to all children, and partly by giving an opportunity to establish a dialogue between religions and world-views within the classroom. In Norway this aim became particularly clear during the last debate about religious education within college-based teacher education that the politically strongest argument for religious education in Norway these days is its contribution to socio-cultural integration (Skeie, 2003).

Apparently the educational authorities expect culture to be highly relevant in the school communication about religion. It also seems that content knowledge about culture (in this case religious culture) in itself is considered to contribute to social harmony. This can be seen as a reflection of the recent public debate about the subject religious education. In this debate the difficulties and controversies around the subject is often considered to be caused by culture (clash of cultures). The debate also focuses on the balancing of interests between different groups of stakeholders (cultural power struggle), and on problems of learning about many religions from an early age (cultural confusion). The strong focus on the intercultural nature of the subject, combined with an understanding of cultures as rather fixed entities, is not necessarily improving the learning situation. There is even a possibility that this increases the very problems that one wants to solve, and that it may cause learning barriers among students. The socio-political context of religious education therefore speaks 
in favour of dealing offensively with inter-cultural situations in religious education, but the relationship between religious education and intercultural education in public schools also present some challenges:

- There might be a problematic relationship on the level of aims, possibly overloading religious education with ambitions of contributing to sociocultural integration and weakening aims related to personal development and knowledge about religion.

- There can be a tendency to exaggerate the significance of intercultural relations in the religious education classroom, defocusing teaching of religion, religiosity and worldviews and over-focusing the issues related to difference, misunderstanding and conflict.

In order to deal with these challenges the advocates of good religious education should consider some of the following suggestions bearing in mind that they are not mutually exclusive:

- To develop a RE-teaching with culture-focusing strategies (complexity enhancement) that can shift focus from reified cultures meeting each other to people meeting people as cultural subjects actively participating in intracultural as well as intercultural processes.

- To develop a religious education teaching with culture-avoiding strategies (complexity reduction) that can save religious education from becoming the only school subject where intercultural relations really are put on the agenda.

- To help the religious education teachers develop skills in establishing and maintaining a third culture as a reflection- and negotiation arena between cultures in the class whenever this is necessary.

- To stimulate religious education teachers to enter into cooperation with teachers in other school subjects in order to establish the minimum of intercultural negotiating arenas necessary for dealing with situations where cultures are activated as an expected or experienced issue and makes subject-learning difficult. Being a responsibility on school level, this should be coordinated across school subjects.

- To encourage religious education teachers to do simple fieldwork in religious communities in order to improve their knowledge about religion-in-practice.

These suggestions are, however, only recommendable if the basis of religious education teaching already is student-oriented and context-sensitive. There is a widespread avoidance of intercultural issues in schools that is not based on careful analysis, but on ignorance, and everyone hoping that somebody else will take care of it. Many argue that awareness of cultural differences is low and that the main problem is to raise awareness of this. This is therefore not a plea for the traditional subject-oriented teacher type with little interest in the students as persons situated in a cultural context. The qualification role of education also has to be related to the actual life-world of students, the realities of their social situation outside school and the communities they belong to.

In this sense it may be possible to move beyond the intercultural perspective, which is connected to traditional plurality, and transcend towards a truly cultural perspective based on modern plurality. Encounters in the religious education classroom should make use of the dynamics of modern plurality as their working basis and employ a cultural approach, contributing to transformative learning. For teachers to have knowledge about, and familiarity with cultural plurality - traditional and modern - is of great importance to religious education (Jackson 2004). It increases consciousness about the context, making it easier to understand the students, thus playing a role in the preparation of lessons. It also helps to deconstruct an essentialist understanding of traditions and of organised religion and consequently opening a door to the world of religiosity and personal life-interpretation of young people. 


\section{BIBLIOGRAPHY}

Barth, F 1994. Manifestasjon or prosess. Oslo: Universitetsforlaget [A collection of essays. An earlier version of the quoted text is published in English: Ethnos 54 (3-4) 1989.]

Baumann, G 1999. The Multicultural Riddle: Rethinking National, Ethnic and Religious Identities. London: Routledge.

Dahl, Ø 1995. Some trends in the Development of the Field of Intercultural Communication in the United States. Intercultural Communication and Contact. Selected Papers form the Nordic Symposium 1994, ed. Dahl, Ø. Stavanger: Misjonshøgskolens Forlag. 28-43.

-- $\quad$ 2001. Mфter mellom mennesker - Interkulturell kommunikasjon. [Encounters between people. On intercultural communication] Oslo: Universitetsforlaget.

Engen, TO (et.al.) 1995. Oppdragelse i et flerkulturelt Norge NOU 12:1995 [White paper on the issue of education in a multicultural, Norway.]

Godykunst, WB and Mody, B (eds.) 2002. Handbook of Intercultural and International Communication. Thousand Oaks, Calif: Sage.

Haus, S 2002a. Ingen er interessert i det du forteller, så derfor er det best å ligge litt lavt. Kommunikasjonsteoretiske refleksjoner i forbindelse med hjemkomst etter utenlandsopphold. Kulturformidling fra internasjonale arenaer, Haus, S, Skeie, G \& Johannessen, ØL. [Communication theory and the understanding of repatriation.] Kristiansand: Norges forskningsråd/Høyskoleforlaget. Kulturstudier 32:39-56.

-- $\quad 2002 b$. Knekk koden, forstå og bli forstått! Om fagfeltet interkulturell kommunikasjon og forholdet til kommunikasjonsteoretiske perspektiver. Kulturformidling fra internasjonale arenaer, Haus, S, Skeie, G \& Johannessen, ØL. [Intercultural communication and communication theory as a research field.] Kristiansand: Norges forskningsråd/Høyskoleforlaget. Kulturstudier. 32:57-68.

Jackson, R 2004. Rethinking Religious Education and Plurality. Issues in diversity and pedagogy. London: RouthledgeFalmer.

Jensen, I 1998. Interkulturel kommunikation i komplekse samfund. [Intercultural communication in complex societies.] Fredriksberg: Roskilde Universitetsforlag.

Kjeldstadli, K (et.al.) (ed.) 2003. Norsk innvandringshistorie 1-3. [History of immigration to Norway.] Oslo: Pax forlag.

Landis, D and Bhagat, RS (eds.) 1996. Handbook on international training. Thousand Oaks, Calif.: Sage.

Nesbitt, E 2004. Intercultural Education. Ethnographic and Religious Approaches. Brighton: Sussex Academic Press.

Skeie, G 2002. The Concept of Plurality and its meaning for Religious Education. British Journal of Religious Education. 25 (1) Autumn:47-59.

-- 2003. KRL - et fag på frammarsj? Norsk Larerutdanning. S $\quad$ 2kelys på allmennlarerutdanningen $i$ et reformeperspektiv, eds. Karlsen, GE \& Kvalbein, IA. [Religious education in teacher training] Oslo: Universitetsforlaget. 189-206. 